\title{
Predictors of multiple treatment failure of antipsychotics in early-onset psychosis
}

1, 3Pina-Camacho, L., ' Dean, H., ${ }^{1}$ Lechler, S., ${ }^{1}$ Sears, N., ${ }^{1}$ Patel, R., ${ }^{1}$ Kartoglu, l., ${ }^{1}$ Shetty, H., ${ }^{1}$ Hotopf, M., ${ }^{2}$ Ford, T., ${ }^{1}$ Kyriakopoulos, M., ${ }^{3}$ Arango, C., ${ }^{1}$ MacCabe, J., ${ }^{1}$ Hayes, R.D., ${ }^{1}$ Downs, J.

P.3.d.017

laura.pina@kcl.ac.uk

1 Institute of Psychiatry Psychology Neuroscience, King's College London \& NIHR South London and Maudsley Biomedical Research Centre; School of Medicine, Universidad Complutense, CIBERSAM, Madrid, Spain

\section{INTRODUCTION}

- In adult-onset psychosis, a number of factors are associated with poor outcomes, including: severity of negative symptoms (NS) at illness onset, presence of premorbid difficulties \& family history of psychotic disorder [1]

- If and how these factors effect psychosis prognosis in children and adolescents is unclear [2,3]

- Furthermore, very little is known about the effect of these risk factors on the response to antipsychotic medications in early-onset psychosis (EOP)

\section{OBJECTIVES \& HYPOTHESES}

- In a historical cohort of individuals with EOP, to investigate the prospective association of demographic and clinical variables at first presentation to services with the eventual development of multiple treatment failure (MTF)

\section{$\rightarrow \underline{M T F}=$ initiation of $3^{\text {rd }}$ trial of novel antipsychotic for psychosis}

- Hypothesis: the presence of NS at first presentation, of premorbid difficulties (e.g. comorbid ASD), and $1^{\text {st }}$ degree family history of psychosis would be positively associated with MTF

\section{METHODS}

Longitudinal naturalistic study of historical clinical cohort of early-onset psychosis in South London $(n=638)$

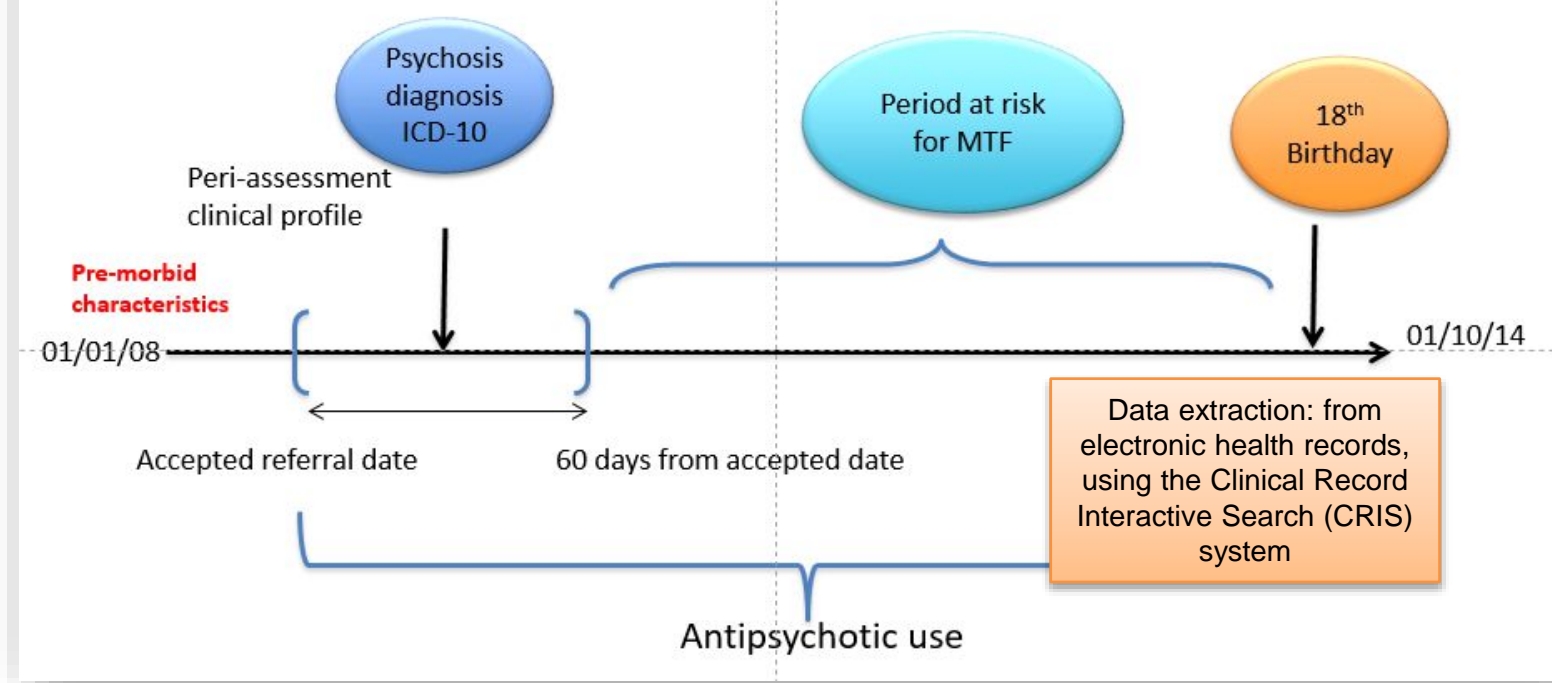

Flowchart of study selection, inclusion criteria and data extraction

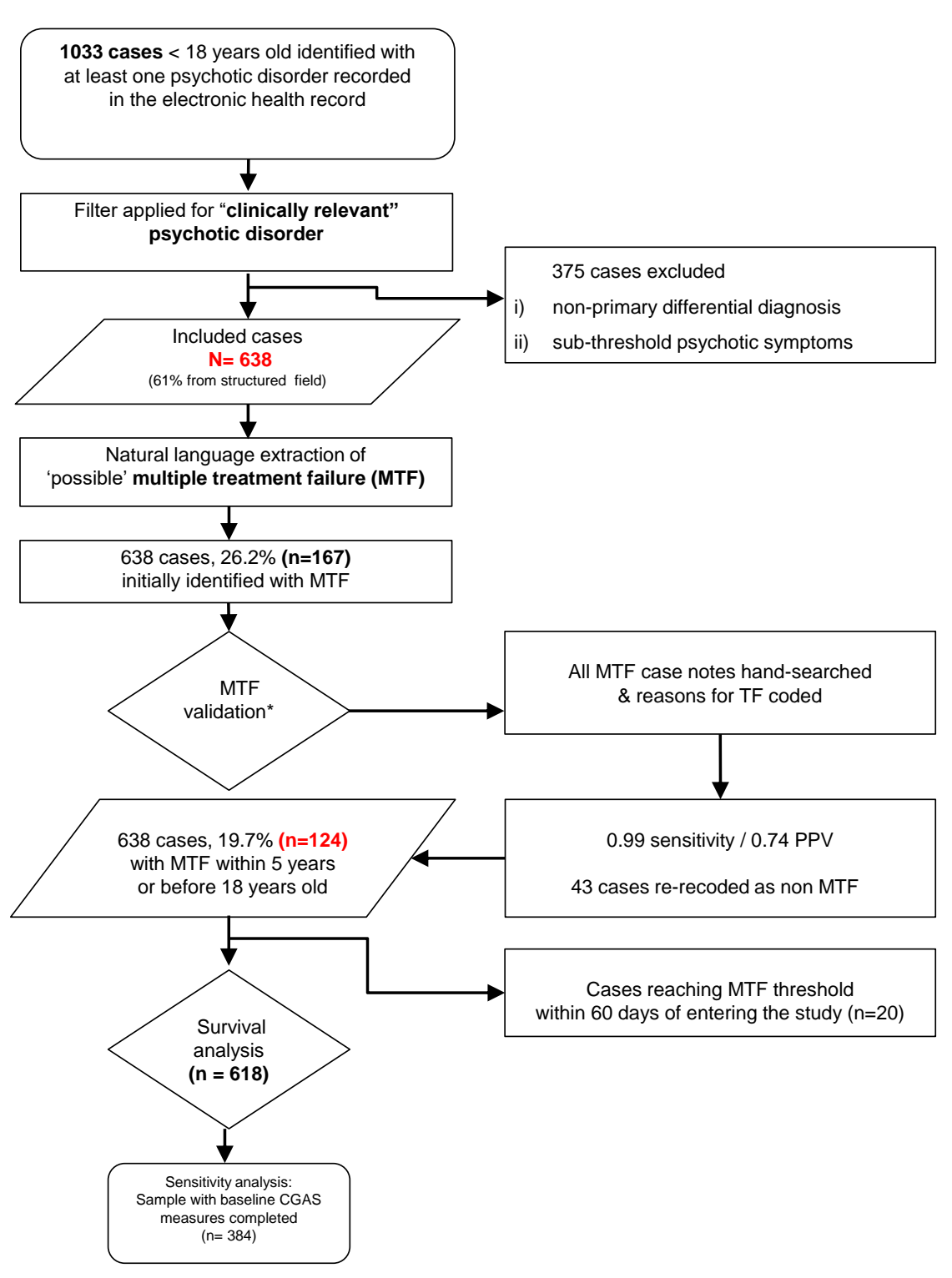

"Three independent raters, hand sead
random selection of non-MF cases

\section{RESULTS}

\section{1) Main characteristics of the sample $(n=638)$}

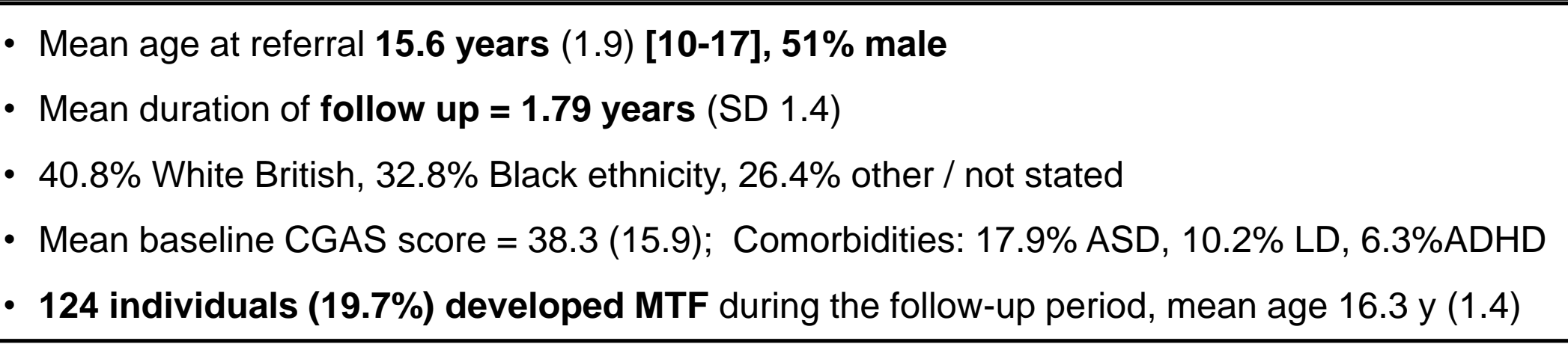

2) Reasons for discontinuing antipsychotics in MTF sample $(n=124)$

口Persistent insufficient response 口Persistent adverse effects 口Persistent non-adherence $\square$ Variety of reasons

alnsufficient response + adverse effects

口Insufficient response + nonadherence

口Adverse effects + nonadherence

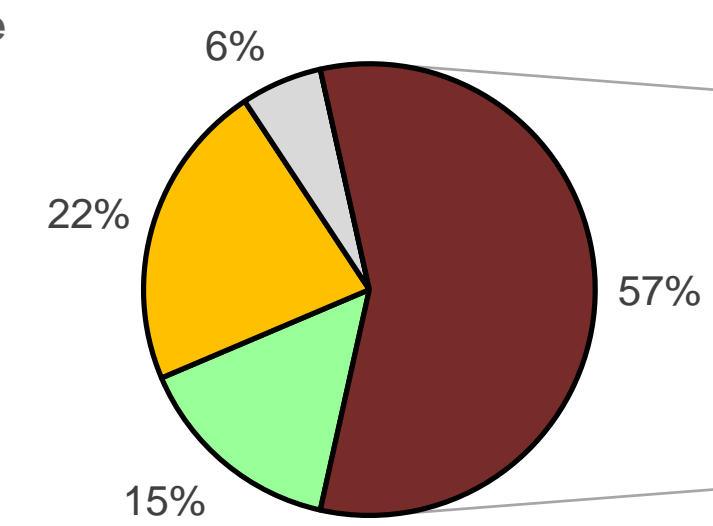
$33 \%$

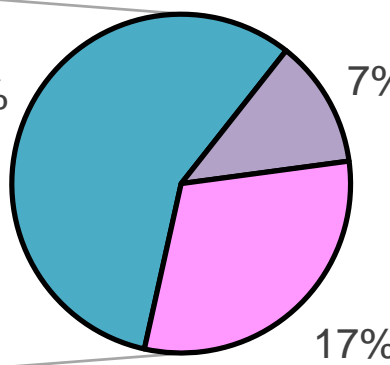

\begin{tabular}{|lcc|}
\hline \multicolumn{2}{|c|}{ 3) CoX regression analysis of the association between } \\
demographic and baseline clinical variables and MTF (n=618)
\end{tabular}

\section{CONCLUSIONS}

Presence of prominent negative symptoms at first presentation to services, co-morbid ASD and first degree family history of psychosis delineate a subset of children and adolescents with psychosis at higher risk of antipsychotic treatment failure

These children may require alternative treatment strategies

\section{References}

[1] Lang, FU., et al., 2013. Psychopathological long-term outcome of schizophrenia -- a review. Acta Psychiatr Scand 127: 173-182; [2] Diaz-Caneja, CM., et al., 2015. Predictors of outcome in early-onset psychosis: a systematic review. Npj Schziphrenia 1: doi: 10.1038 / npjschz.2014.5; [3] Schneider, C., Papachristou, E., Wimberley, T., Gasse, C., Dima, D., MacCabe, J.H., Mortensen, P.B., Frangou, S. 2015 Clozapine use in childhood and adolescent schizophrenia: A nationwide population-based study. Eur Neuropsychopharmacol 25, 857-863. Funding Sources: the Clinical Records Interactive Search (CRIS) system is funded and developed by the National Institute for Health Research
(NIHR) Mental Health Biomedical Research Centre at South London and Maudsley NHS Foundation Trust and King's College London and a joint infrastructure grant from Guy's and St Thomas' Charity and the Maudsley Charity (grant number BRC-2011-10035).

Disclosures: Dr Downs is supported by a Medical Research Council (MRC) Clinical Research Training Fellowship MR/L017105/1. Mr Dean and Lechler received salary support from the Foundation of Professional Services to Adolescents, UK. Dr Hayes is funded by a $n$ MRC Population Health
Scientist Fellowship (MR/J01219X/1). Dr Pina-Camacho and Dr Arango have held a grant from Instituto de Salud Carlos III, Spanish Ministry of Economy and Compelitivess, CIBERSAM and the Alicia Koplowitz Foundation. Professors Hotopf. Dr MacCabe and Mr Shetty receive salary support from the National Institute for Health Research (NIHR) Mental Health Biomedical Research Centre 